Supplement of Clim. Past, 12, 697-711, 2016

http://www.clim-past.net/12/697/2016/

doi:10.5194/cp-12-697-2016-supplement

(C) Author(s) 2016. CC Attribution 3.0 License.

(c) (i)

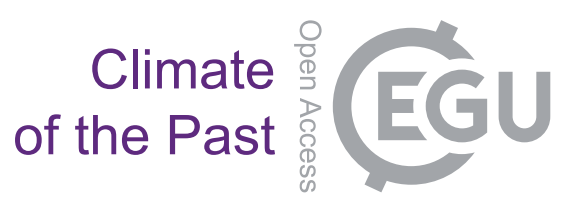

Supplement of

\title{
Millennial-scale vegetation changes in the tropical Andes using ecological grouping and ordination methods
}

Dunia H. Urrego et al.

Correspondence to: Dunia H. Urrego (d.urrego@exeter.ac.uk)

The copyright of individual parts of the supplement might differ from the CC-BY 3.0 licence. 


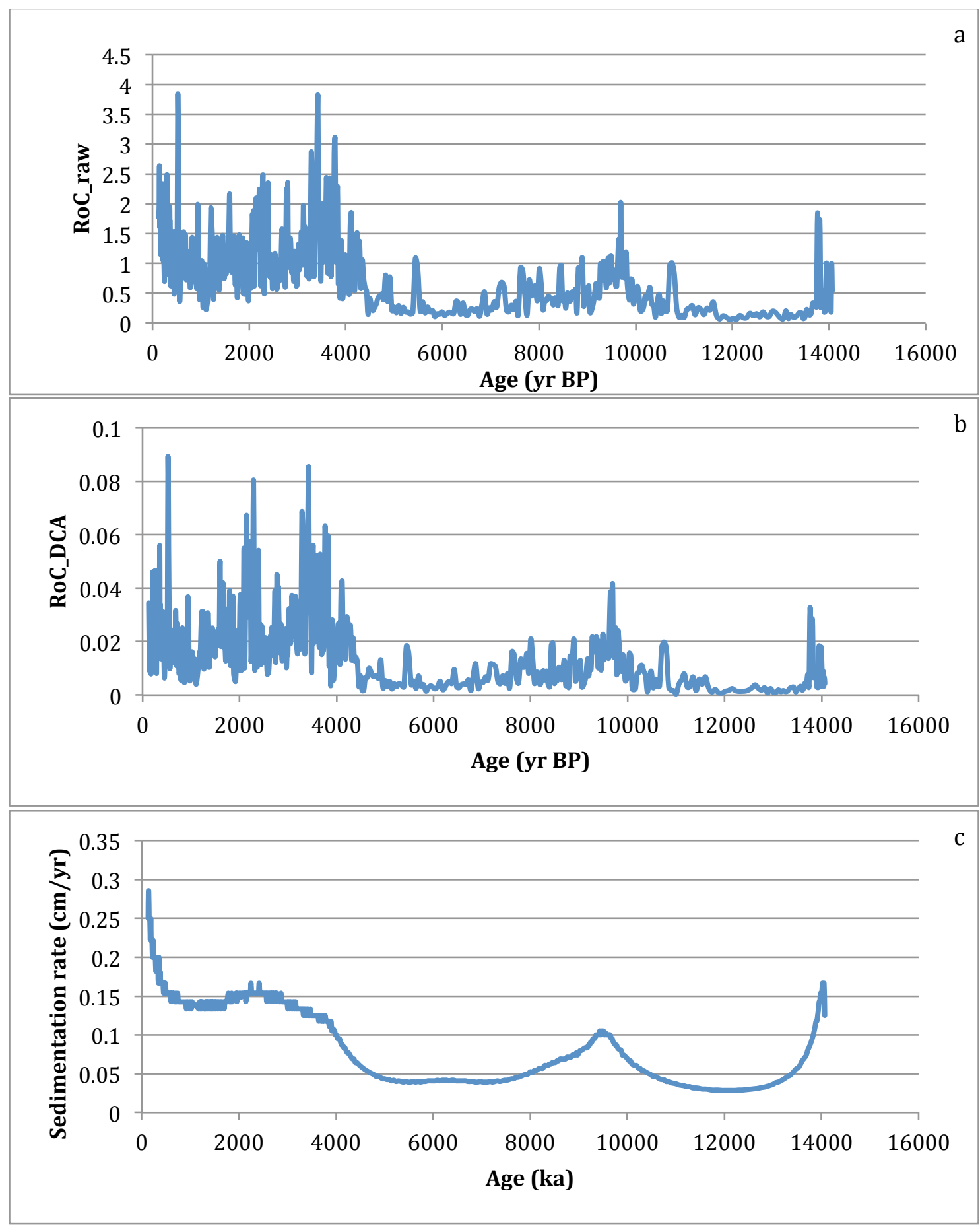

Figure S1. Rates of change $(\mathrm{RoC})$ and sedimentation rate calculated for La Cocha record. a: RoC calculated based on Euclidean distance between subsequent samples using raw percentages, plotted against age. b: RoC calculated based on a Euclidean distance between the first four DCA axes, plotted against age. c: Sedimentation rate plotted against age. 